\title{
Kamusal Mekânlarda Deneyim ve Kullanıcı Merkezli Tasarım
}

Bedriye Begüm Nazlı Erap

Dr. Öğr. Üyesi Sennur Hilmioğlu

Makale Geliş Tarihi: 16.04.202

Prof. Dr. Füsun Seçer Kariptaş

\section{Özet}

Bir mekânın var olma nedeni olarak insan ele alındı̆ı̆nda aslında tasarımın odak noktası olduğu görülmektedir.

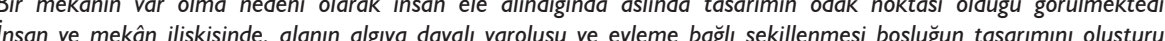
Bu bossluk, hareket ve davranıșlardan etkilenen bir alan olduğu sürece olası problemler karsısinda kullanııı odakı cö̈zümler aranmaktadir. Mekânın kullanılabilirlig̈inden gelen sorunlara cözüm arayısı beraberinde iyi bir tasarım ihtiyacını doğurmaktadır. Bu bağlamda, kullanııı merkezli tasarım (UCD- User Centered Design) kavramının süres üzerindeki etkilerini gözlemlemek mümkündür. Ayrıca sözü edilen döngüdeki kullanııı deneyimi tasarımı kavramının değerlendirilmesi ve ölçümlenmesi, tüm tasarım disiplinlerinde olduğu gibi iç mimaride ve kamusal alanlarda da sonucu etkileyen bir katma değer oluşturmaktadır. Son dönemlerde tasarlanan geleneksel mimari yapılardan öteye, kullanıc davranıșıı öļ̧üt alan yenilikçi, çözümcü ve etkileșime dayalı kamusal alanların tasarımları ele alındı̆̆nnda, kullanıc merkezli tasarım ve kullanıc deneyiminin iç mekâna nitelik katan etkisi gözlemlenmektedir. Bu çalıșmada insanın bir kullanııı olarak değerlendirip, deneyim ve alıskanlıklarına yönelik mekân tasarımı arayışları kamusal mekân örnekleri üzerinde iç mimarlık bağlamında incelenmiş ve mekân-kullanıc i iliģkisi üzerinden değerlendirilmiştir.

Anahtar Kelimler: Kullanııı Merkezli Tasarım, Kullanııı Deneyimi Tasarımı, Tasarım Yaklaşımları, İnsan ve Mekân Kamusal Mekân Tasarımı

EXPERIENCE IN PUBLIC SPACES AND USER CENTERED DESIGN

\section{Abstract}

The human is the focal point of design when considering him as there as on for existence of the space. In the connection between human and place; the existence of the space based on perception and taking a form as action create the design of space. This space as long as it is an area that is affected by movement and behavior user-centered solutions are searched against possible problems. Here, these arching for solutions of the problems which is becoming from the are searched against possible problems. Heability of the space creates the need for good design. The design; it creates a design cycle by evaluating the interaction received from the user at the end of the process as; determining the need, identifying and solving possible problems, providing flexible use with technology and transforming it into an aesthetic form. The validity of this cycle is seen in multidisciplinary areas from the interfaces of digital screens to architectural design, city planning, industrial design, and visual media of communication design. In the common purpose of all design approaches, an ideal design is based on human-centeredness that serves firstly from individual to society. In this context; it is possible to observe the effects of the human centered design (HCD) concept on the process. In addition, in the mentioned cycle; evaluating and measuring the concept of user experience design creates an added value that affects the result in interior architecture and public spaces as well as in all design disciplines. Recently, beyond the traditional architectural structures, when considering the designs of innovative, analytical and interactive public spaces based on userbehavior, it is observed that the humancentered design and user experience add quality to the interior space. In this study, the search for space design for the experience and habits of the human being as a user has been examined in the context of interior architecture on public space examples and evaluated through the space-user relationship.

Keywords: User Centred Design (UCD), User Experience Design (UXD), Design Approaches, Human and Space, Public Space Design

Bedriye Begüm Nazlı Erap, Haliç Üniversitesi, Lisansüstü Eğitim Enstitüsü, Lç Mimarlık Programı, Yüksek Lisans Öğrencisi, İstanbul. E-posta: bbegumnazli@gmail.com, ORCID ID: 0000-0003-4606-935 Dr. Öğr. Üyesi Sennur Hilmioğlu, Haliç Üniversitesi, Mimarlık Fakültesi, iç Mimarlık Bölümü, İstanbul. E-posta: sennurhilmioglu@halic.edu.tr. ORCID: 0000-0002-8162-3407 


\section{Giriş}

İnsanın varoluşundan bugüne barınma ve korunma intiyacı ile başlayan, teknoloji ile konfor ihtiyacına doğru uzanan tüm bu süreçte yapılan her tasarım, bir probleme yanıt aranması sonucu geliştirilmiştir. Günümüzün teknoloji ile evrimleşen toplumsal yapısında, daha iyiyi talep eden, kolay yaşamı benimsemiş bireysel kullanıcıların varlığı ile karşılaşmaktayız. Bugün gerek bir mekân gerekse bir nesne adına yapılan tasarımlarda estetik olmasının yanı sıra öncelikle probleme çözüm olma kaygısı güdülmektedir.

Intiyaca dayalı çözüm arayışındaki her tasarım temelinde insanın beden, eylem, davranış, algı ve yaşam biçimi ile hacim kazanmıştır. İnsan bedenini ölçüt alan antropometrinin ergonomiye yön vermesi, yapabilitesi ve eylemlerin evrensel tasarım ilkelerini oluşturması gibi temel tasarım yaklaşımlarında da bu insan merkezlilik gözlemlenmektedir. Gerek ergonomi gerek evrensel tasarım gerekse katılımcı tasarım yaklaşımı olsun her süreçte insan eylemlerinin etkileri ayrı ayrı değerlendirildiğinde bu ortak payda ile karşılaşılmaktadır. Burada son dönemlerde özellikle nesne-insan ilişkisinde çok karşılaşılan bir kavram olarak insan merkezli tasarım kavramından (HCD) sadece yeni bir tasarım yaklaşımı biçimi olarak değil, multidisipliner alandaki tüm tasarım süreçlerinin merkez noktası olarak da söz edilmektedir. Bu insan merkezli tasarım kavramı hümanist bir düşünce kavramı olan ve insanı yaşanılan doğa-kültürde merkeze alan insan merkezcilik ideolojisinden tamamen bağımsız olarak, insanı bir kullanıcı olarak değerlendirmektedir. Yaşadığı toplumda teknoloji ve kültürün birlikteliğinde üretici-tüketici olarak insan, yaşadığı toplumsal yapıda gruplar halinde veya birey olarak kullanıcı formuna bürünmüştür. Burada tasarım ve mimar karşısında kullanıcıya dönüşen insan mekânla ilişkisinde kullanıcı merkezli tasarım (User centered design - UCD) kavramı üzerinden ele alınmaktadır. Kullanıcı merkezli tasarım, kullanıcı-nesne ve mekân ilişkisini inceleyerek iyi bir tasarım nihai sonucuna odaklanır. İyi bir tasarımdan söz edebilmek için, yapının oluşumu, dönüşümü ya da geliştirilmesi noktasında intiyaca dayalı en ideal çözümü sunması gerekmektedir. İhtiyacın belirlenerek olası problemlerin tespit edilmesi, teknolojiyle esnek kullanım sağlanarak estetik bir biçime büründürülmesi sonucunda kullanıcıdan aldığı etkileşimin değerlendirilmesiyle bir tasarım döngüsü oluşmaktadır. Bu döngünün geçerliliği, dijital ekranların ara yüzlerinden, mimari tasarıma, şehir planlamaya, endüstriyel tasarıma, iletişim tasarımının görsel mecralarına kadar multidisipliner alanlarda görülmektedir. Tüm tasarım yaklaşımlarının ortak amacında önce bireye, devamında topluma hizmet eden kullanıcı odaklı çözüm arayışları yer almaktadır.
Evrensel tasarım bağlamında bakıldığında; kullanıcısına hizmet eden bir tasarım, bireyin yaşam alanını en verimli noktaya getirmeyi amaçlar ve bu yönde çözüm önerileri sunar. O halde bir yapının evrensel tasarım normlarına uygun olarak planlanmasında insan merkezli tasarım kuramının etkisi gözlemlenebilir. Bununla beraber, planlanan yapının kullanıcı kitlesinin deneyiminin ölçümlenmesi de tasarımda verimlilik adına artı değer üretmekte hatta bazı noktalarda sistemin ana mekanizmasını bile oluşturabilmektedir. Özellikle bugünün detaylı hesaplanmış kamusal alanlarında uygulanan ergonomik tasarımın ve evrensel tasarım kurallarına uygun icra edilmiş bir mimari tasarımın, kullanıııı üzerindeki etkilerine bakıldığında, kullanıcı merkezli tasarım yaklaşımı gözlemlenmektedir. İnsan kullanıcı olduğu mekânın bir diğer taraftan da bireysel ve toplumsal hareketleri ile şekillendiricisi konumundadır. Burada mekân, deneyim ve etkileşim sonucu kültürel etkenlere bağlı bir oluşum ve dönüşüm sonucu şekillenmektedir (Erap, Yurttaş, Kariptaş, 2021). İnsanın bir kullanııı olarak ele alınıp, intiyaçları ve yapabilitelerini bireysel boyuta indirgeyerek çözüm arayışına giren her tasarımın toplumsal oranda bir tasarım değerine sahip olduğundan da söz etmek mümkündür.

\section{Tasarım Yaklaşımları ve Kullanıcı-Tasarım İlişkisi}

Bireyin; çalışma ve yaşam alanların da nesnelerle ilişkisi, mekânla iletişimi, rutin davranışlarında karşılaştığı yeni durumlarla etkileşiminden çıkacak sonuçla; tüm yaşamı sürecinde tasarıma gösterdiği esneklik uyumuna, fonksiyonelliğine, yapılabilirliğine ve kullanabilirliğine intiyaç duyulmaktadır. Kullanıcının çevresi ile bu değerler altında etkileşimini inceleyen ergonomi bilimi, günümüzün tüm tasarım birimlerinde olduğu gibi iç mekânda da insanı bir kullanıcı olarak değerlendirip merkeze alan bir tasarım yaklaşımı olarak karşımıza çıkmaktadır.

Kullanıcısının ideal çalışma ve yaşam kalitesini artırmayı hedefleyen ergonomi tasarımı, insanı fizyolojik yapabilirlikleri, kültür farklılıkları, algısal ve sezgisel bütünlüğü gibi özellikleri ile bireysel bazda incelemektedir. Bu incelemede hedef kitlenin neredeyse \% 99'una ulaşmayı hedefleyen ergonomi tasarımı ve evrensel tasarım kavramlarının ortak kesişimleri görülebilir. " Evrensel Tasarım" kavramı; fiziksel ve entelektüel açıdan değişen olanakların sadece birkaç kişinin özel durumu olmadığı, insan olmanın ortak bir özelliği olduğu gerçeğinden yola çıkarak geliştirilmiştir. Bu kavram, tasarlanmış çevrenin, baştan itibaren mümkün olduğunca fazla insan için kullanışlı ve sorunsuz bir şekilde işlemesini hedeflemektedir (Hilmioğlu, 2017). 1980'li yıllarda ortaya atılan evrensel tasarım ilkeleri doğrultusunda kategorisel bir planlama ile toplumsal gruplara yönelik çözüm önerileri sunma şeklinde 
bir çalışma sistemi düzenlenmiş, ancak bu sistemin zaman zaman tüm bireylerin problemlerini karşılayamadığı görülmüştür. Bu konuda Donald Norman, herkese uygun tek bir çözüm arayışını bir sorun olarak görmektedir. " Ortalama insan diye bir şey yoktur. Genellikle herkes için tek tip bir tasarım yapma çözümüne erişen bir tasarımcı için bu spesifik bir sorun teşki edebilir. Ayrıca gözlemlere göre evrensel bir tasarımın $\% 90$ ve üzeri oranda insana hitap etmesi beklentileri karşılamaktadır." (Norman,2016). Fakat Norman'ın bu olguda hesaplamalarına göre; dünyada 7 milyar insan varken \% 99'u için yapılan tasarım dahi dünyanın yüzde dilimine bakıldığında 70 milyon insan dışarıda kalmaktadır (Norman, 2016). Burada herkes için tasarım olgusunun tam anlamıyla karşılanabilmesi için farklı yöntemlerin arayışına girilmesi gerektiğini görmek mümkündür. Bu düşünce doğrultusunda herkes için yapılan değerlendirme özünde birey hedef alınırken, toplumun bir kategorisi için yapılan tasarım bireysel baza indirgenmekte ve her tasarım yaklaşımında insan merkezli tasarım kavramı açı̆̆a çıkmaktadır. İnsan merkezli tasarımın bir takım bakış açılarına göre de 1950'lerin sonlarında engelsiz tasarım kavramı ile başlayan ancak evrensel tasarım kavramını takip eden bir yaklaşımın ortaya çıktığı görülmektedir. Dünyanın farklı ülkelerinde "evrensel tasarım" kavramını çağrıştıran değişik terimler kullanılmaktadır. "Herkes için tasarım" (design for all), "kapsayıcı tasarım" (inclusive design), "kullanıcı odaklı tasarım" (user needs design), "gerçek yaşam için tasarım" (real life design), "ömür boyu için tasarım" (life spandesign), "kuşaklararası tasarım" (transgenerationaldesign) bunlardan bazılarıdır.1 İnsan merkezli tasarım yaklaşımının, her ne kadar tüm tasarım yaklassımlarını takip eden bir manifestoya sahip gibi görünse de aslında multidisipliner tasarım alanlarının ortak sürecini kapsadığı görülmektedir (Şekil 1).

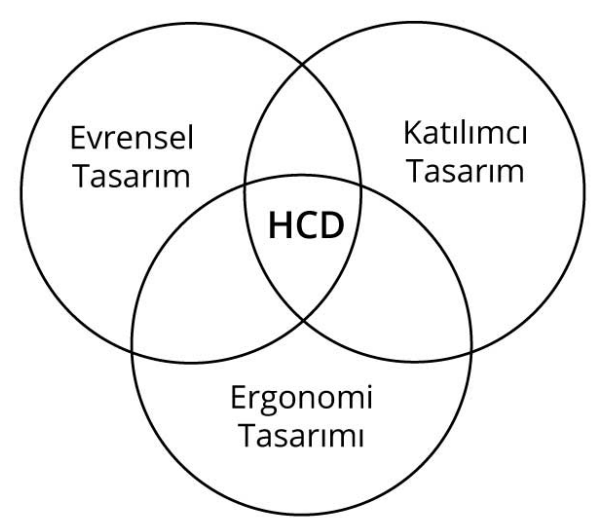

Şekil I. Insan Merkezli Tasarım ve Tasarım Yaklaşımları
Kullanıc merkezli tasarım yaklaşımı ile aynı yıllarda ortaya çıkan insan merkezli tasarım (human centered design) yaklaşımının, ergonomi ve antropometri bilgileri ile bireyin algısal ve sosyo-kültürel özelliklerinden doğan verileri birleştiren tasarım ilkelerini barındırdığı görülmektedir (Acırlı, 2020). Burada söz edilen insan merkezli tasarım ve kullanıcı merkezli tasarım kavramı bağımsız ya da dolaylı iki kavram değildir. ISO' nun açıklamasına göre; "Insan merkezli tasarım" terimi, bu belgenin sadece kullanıc modeli üzerine kurgulanması değil, bir dizi paydaş üzerindeki etkilerini de vurgulamak için "kullanıcı merkezli tasarım" yerine de kullanılmaktadır. Bununla birlikte, pratikte, bu terimler genellikle eş anlamlı olarak kullanılmaktadır (ISO 9241-210, 2019). Bugün, kullanıcı merkezli tasarım yaklaşımı ISO (International Organization of Standardization) tarafından onaylanmış, 9241-210 kaynağınca teknik standartları belirlenmiştir. Burada tasarımın insan merkezliliğinden bahsederken teknik detayların ve deneyimin ölçümlenmesinde kullanıcı odaklılığından söz edilmektedir.

Kullanıcıların ihtiyaçlarını tespit etmek adına ergonomi ve kullanılabilirlik bilgileriyle entegreli çalışması ile kullanıcı merkezli tasarımın diğer yaklaşımlarla kesiştiği görülmektedir.

Kullanıcı merkezli tasarım yaklaşımı ergonomik kriterlerin uygulanması ve kullanılabilirlik teknikleri bilgisi ile kullanıcıların intiyaçlarına ve ilgi alanlarına odaklanan etkileşimli sistemlerin gelişimini ele almaktadır. Bu yaklaşım insan sağlığını, erişilebilirliğini, sürdürülebilirliğini iyileştirmekte ve bunların farklı etkilerini hesaba katarak sağlık, güvenlik ve kullanıcı performansının etkileşimini yansıtmaktadır (Chammas, 2015).

\section{Mekânda Kullanıcı Deneyimi}

Mekân algısı genel anlamda beyinde başlayan fiziksel aktivitelerin, insanın çoklu sensörleri doğrultusunda bulunduğu mekânla etkileşimi sonucu oluşmaktadır. Bir mekânın kullanımı insanın zihninde oluşturduğu algısı ve bedeni ile kavrayışındaki bilinçdışı eylemlerinin ardında gözlemlenebilir. Insanın bulunduğu yeri algılama biçimi, görsel ve sezgisel algıya dayalı hafızadaki bilgi birikiminin oluşturduğu etkileşimlerle ilişkilidir. Bu etkileşim gerek deneyimleri gerekse sezgilerden süregelen bedenin eylemleri doğrultusunda gerçekleşmektedir. Mekânla etkileşimde, mekânın geometrik biçim bilgisi, insanın eklemlerin açısı ve kemiklerinin pozisyonuyla doğrudan ilişkilidir (Dervişoğlu,2008). Bu etkileşimi verimli kılmak adına insanın anatomik özellikleri, fiziksel hareketleri, sezgisel algısı ve antropometrik ölçüleri tasarıma yön vermektedir. İnsan bedeniyle mekânda var olur, zihni ile kavrar, eylemleri ile etkileşimde bulunur ve bu etkileşim ile mekânı deneyimler. Bu olgu Schulz'un şu sözü ile özetlenebilir: "İnsanın bulunduğu yer 
mekânın merkezidir ve mekân insanın eylemlerine göre şekillenir"(Schulz, 1971). Bir mekânın varoluşu ve aktif ritmi; insanın alanın boşluğundaki eylemleri ve etkileşimi ile mümkündür. Hatta bir mekândan elde ettiği deneyimlerinin diğer mekânlarla ilişkisi de bu oluşumun etkin bir parçasıdır. Her mimari dokunuş deneyimi çok duyusaldır; boşluk, madde ve ölçek nitelikleri; göz, kulak, burun, cilt, dil, iskelet ve kas tarafından eşit olarak ölçülür (Pallasmaa, 2005). Mimarinin insan bedeni üzerinden ölçümlenmesi, antropometrinin oluşumu, evrensel tasarım arayışı beden-mekân ilişkisindeki somut bir arakesit, bir diğer açıdan bedenin eylemsel varlı̆ı̆ı ın mekânı şekillendirmesi olarak da görülebilir. O halde kullanıcı merkezl tasarım kavramı, mimari tasarım bağlamında bakıldığında insanın mekân ve ona bağlı nesnelerle etkileşimi ve iletişimidir. Burada insan birey olarak ele alınsa da mekân yalnızca salt bireye dayalı bir boşluk olarak değil toplumsal bir alan niteliğinde de kullanıılarının etkileşiminde var olmaktadır. Toplumsal mekân toplumun mekânıdır. İnsan sadece kelimelerle yašamaz; her 'özne' kendini tanıdığı ya da yitirdiği, dolayısıyla yararlandığı ya da değiştirdiği bir mekânın içine yerleşir (Lefebvre, 1991). Kullanıcı bir birey olarak mekânı şekillendirirken toplumun bir öznesi niteliğindedir. Mekân kendi toplumunun şekillendirmesi ölçüsünde kullanıcının algısı, eylemleri, alıskanlıkları ve deneyimi önem kazanmaktadır. Deneyimin arkasında zihin-beden-eylem olarak tümüyle insanı ele almak bir ölçü birimi olarak görülmüştür. 90'lı yıllarda ortaya çıkan başta insan merkezli tasarım olarak ele alınan kullanıcı merkezli tasarım kavramı çoğunlukla endüstriyel tasarımlar, ürün kullanılabilirliği ve dijital arayüzlerin kullanımı devamında otomobil sektörü üzerinden değerlendirilmiş olsa da bugün tüm tasarım disiplinlerinde olduğu gibi mimaride de etkin varlığını gözlemlemekteyiz. Mekân ve kullanıcı etkileşiminde kullanılabilirliğin ölçümlenebilmesi kullanıcı deneyimine dayalı bir yapıdır. Bu yapıda; mekânda, etkileşim tasarımı ve kullanıcı deneyimi döngüsünün kullanıı merkezli tasarımla ilişkisini gözlemlemekteyiz (Şekil 2).

Kullanıcı deneyimi tasarımı kavramı bütünüyle;

- Bir mekâna giriş sağlayan kullanıının çoklu duyusal yönleri ile mekânı algılaması,

- Yapabilirlikleri doğrultusunda nesnelere erişebilmesi,

- Buradaki boşluk ve nesnelerle etkileşimindeki kullanılabilirliğin sağlanması,

- Bu etkileşim ile ortamı deneyimlemesi ve

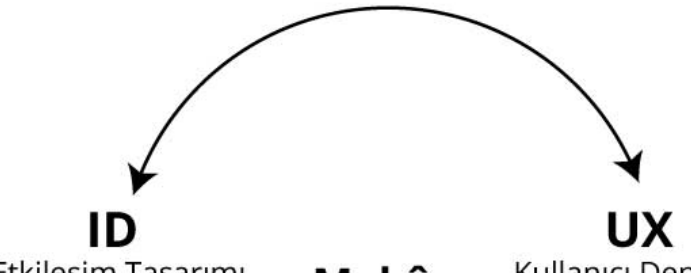

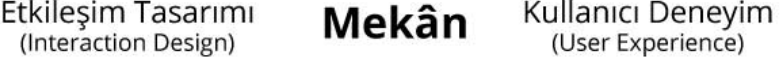
(Interaction Design)

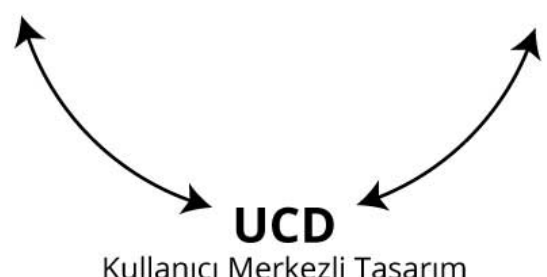

Kullanıcı Merkezli Tasarım (User Centred Design)

Şekil 2. Mekâna bağlı Kullanıı Deneyimi Tasarımı (UXD)

- Bu deneyimi tekrar eden girişlerinde ya da diğer mekân iletişimlerinde kullanması sürecini içerir (Şekil 3).

Tasarımcıların ve mimarların kullanıcı etkileşiminden edindiği geri dönüşleri ölçümlemesi ve değerlendirmesi ile elde ettiği veriler mekânın şekillenmesini

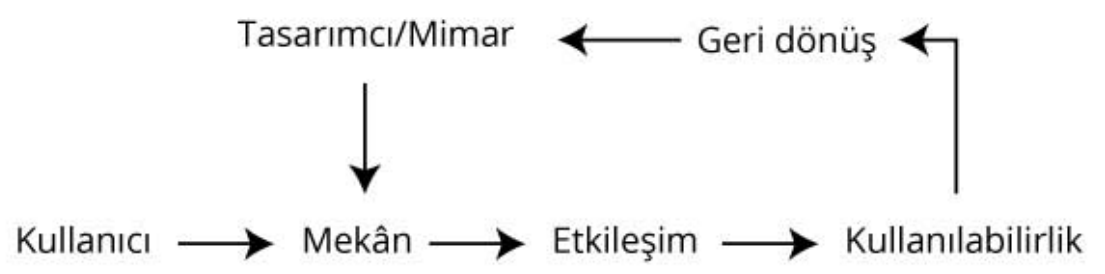

Şekil 3. Kullanıcı Deneyimi Tasarımı Süreci (UXD)

etkileyecek bir faktör olarak karşımıza çıkmaktadır. Bu sayede mekânın algılanabilirliği ve kullanılabilirliği maksimum verimlilikte sağlanmakta ve estetik detayların eklenmesi ile deneyime dayalı, kullanıcısına hizmet eden bir mimari yapı olarak tasarım değeri oluşturmaktadır. Dijital ara yüz tasarımları, bilgisayar tabanlı sistemler ve ekran tasarımları gibi interaktif mecralar üzerinde bir çalışma alanı olarak aktif varlığını kabul ettirmiş 
kullanıcı deneyimi tasarımı; bir ölçümleme birimi olarak net verilerle mimaride henüz yerine oturmuş değildir. Fakat varlığının etkisi ve önemi konusunda diğer tasarım yaklaşımları ile bağdaşık yapısı sonucu araştırma konusu haline gelmeye başlamıştır. Deneyim üzerine tasarlanan yapılar ya da yapının kullanılabilirliğinin test edildiği çeşitli yöntemlerde de bu farkındalık görülmektedir.

\section{Kamusal Örneklerde Deneyime Dayalı Mekân Tasarımları}

Günümüzde kullanııının olası davranışları hesaplanarak kullanıcıya bireysel ya da toplumsal etkileşimde bulunabilecekleri alanlar oluşturmak üzere, deneyime dayalı kullanıcı merkezli mekân örneklerinin inşası ile karşılaşmaktayız. Kendi coğrafyalarında benzersiz sayılan bu örnekler mimariyi statik olmaktan çıkararak dinamik ve insan hareketine göre şekil alan bir yapıya dönüştürmektedir. Bu yapılarda form işlevi takip ederken insanı, mekânı ve hizmeti kullanmaya davet eden bir rolü üstlenmektedir. Son günlerde işlevsel etkileşim yapıları olarak ele alınan Avrupa menşeli kamusal mimari örnekler ile karşılaşılmaktadır.

\subsection{Oodi Helsinki Merkez Kütüphanesi}

Insan merkezli tasarımın uygulandığı yapıya ilk örnek, kullanılmak üzere tasarlanmış boşluklara sahip bir kütüphane olarak tasarlanan Oodi Helsinki Merkez Kütüphanesi (Oodi Helsinki Central Library) ele alınabilir (Resim 1).

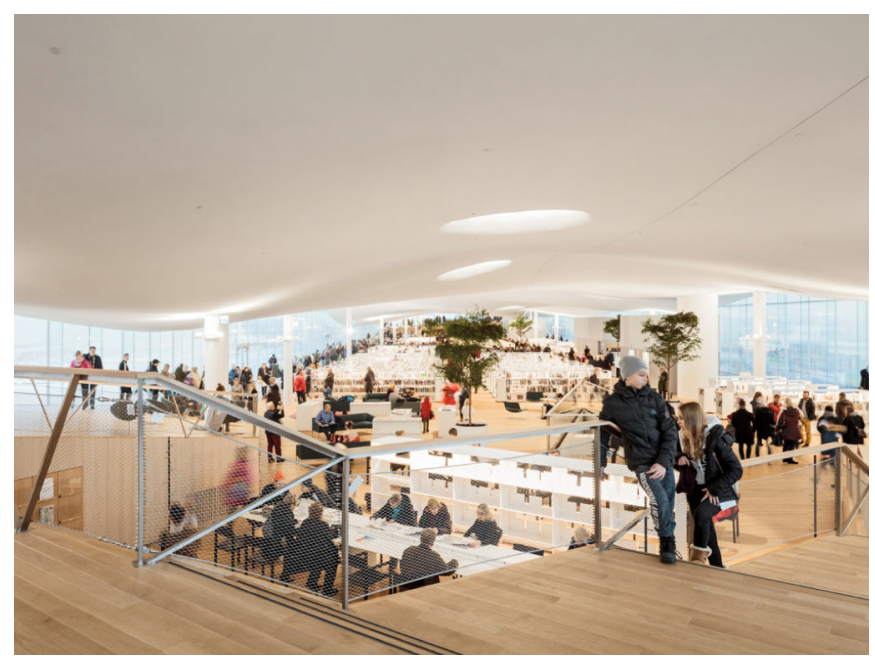

Resim I. Helsinki Oodi Merkez Kütüphanesi-Finlandiya²
Bu yapının tasarımı kütüphanenin işlevlerini üç farklı seviyeye ayırma fikrine dayanmaktadır: Aktif bir zemin kat, sakin bir üst kat ve daha spesifik fonksiyonları içeren kapalı bir ara hacim. ${ }^{3}$ Oodi'nin zemin katı, girişteki hareketlilik nedeniyle geniş bir lobi olarak tasarlanmış halka açık tesisler ve etkinlik alanları içermektedir. İkinci katta ortak çalışma alanları, aktivite, öğrenme ve etkileşime hizmet eden odalar mevcuttur. ${ }^{4}$ Ayrıca ortak etkileşimi içeren stüdyolar, toplantı alanları, oyun odaları ve atölyeler de yine bu katta konumlanmıştır.

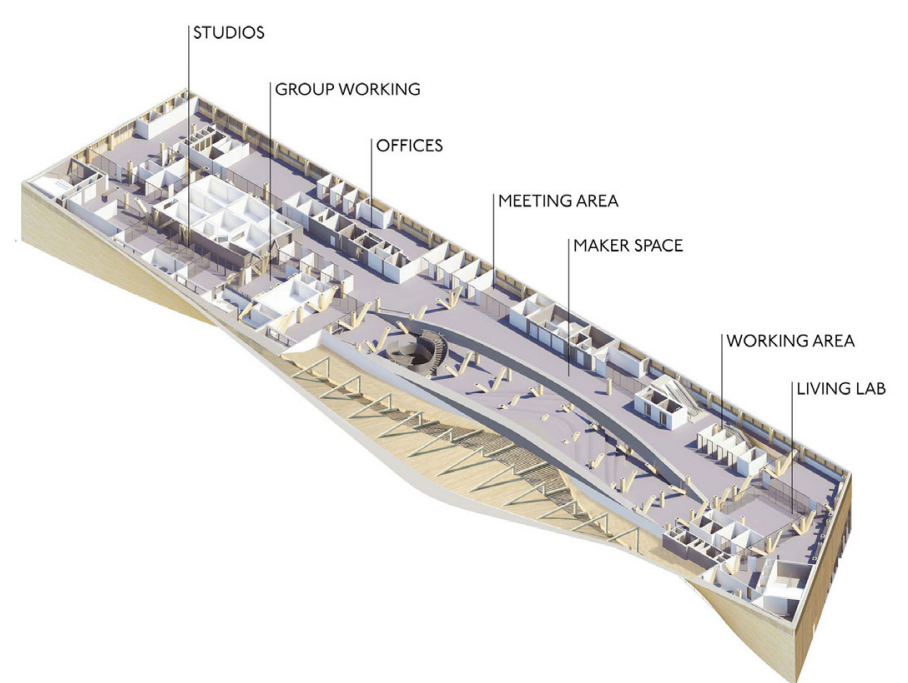

Resim 2. Helsinki Oodi Merkez Kütüphanesi-Finlandiya 2. Kat Planı ${ }^{4}$

Üçüncü kat ise hareketin minimuma indirgendiği, sakinlik ihtiyacı duyan bir alan olarak kütüphane olarak tasarlanmış, okuma alanları ve kafeler ile araștırma ve dinlenme alanı olarak planlanmıştı. Ayrıca kentle birleşimini sağlayan geniş bir seyir terası da bu bölümde konumlandırılmıştır. Tamamen kullanıcıların talepleri, davranış ve etkileşim sonuçları, kullanıcı deneyimi göz önüne alınarak hesaplanmış ve insan merkezli tasarım bu mimari yapıda vücut bulmuştur.

\subsection{Forum Groningen}

Davranış modeli üreten bu mimari yapılara bir diğer örnek de 'iletişimsel Mimarlık' kavramıyla kurulan NL Architects' in Hollanda'da toplum davranışı üzerine tasarladığı bir kültür merkezi olan Forum Groningen'dir (Resim 3)

${ }^{3}(\mathrm{Url}-3)$

${ }^{4}(\mathrm{Ur}-4)$ 


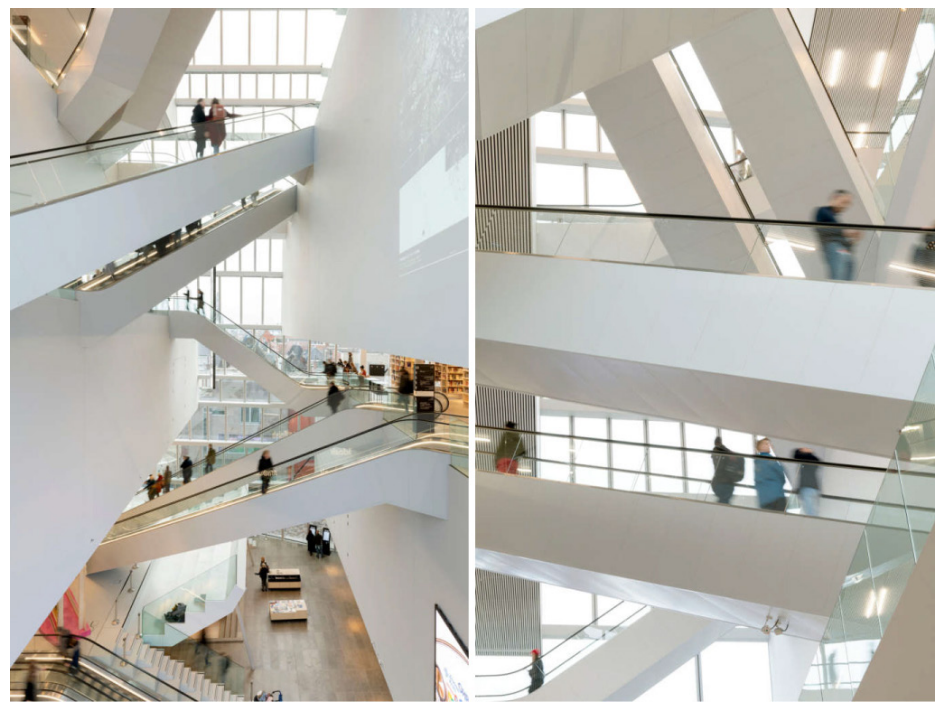

Resim 3. Forum Groningen-Hollanda ${ }^{5}$

Içerisinde sinema salonları, sergi alanları, toplantı solanları, restoran ve kitaplarla dolu olan bu yapı tek başına bir alışveriş merkezi, kütüphane, müze ya da sergi alanı olarak konumlanmayan çok işlevli bir bina olarak karşımıza çıkmaktadır. Kamusal etkileşim alanlarını birleştirerek bu alanlardaki geleneksel sınırları ortadan kaldıran bir yapı örneği sunmaktadır. Bilgi ve fikir alışverişini hızlandırmayı hedefleyen bir bossluk yapısı ile sinema, kitap koleksiyonu, fuar, oditoryum gibi tüm işlevleri birbirine bağlayan mekânsal bir ara yüz olarak çalışmaktadır ${ }^{5}$. Kullanıcının mekânla etkileşime girmesi ve iletişimde bulunmasını amaçlayan bu mimari yapı da kullanıcı deneyimini değerlendiren insan merkezli bir tasarımın bir mekânda ne şekilde uygulanabileceğini, nasıl farklı yaklaşımlarda bulunup artırılabilir değerler üretilebileceğini örneklemektedir.

\section{Sonuç}

Mimari tasarımın kullanıcıları özelinde ve toplum üzerinde olumsuz etkilerinin önlenebilmesi hatta yeni değerler oluşturarak problemlerinin en üst verimlilikte çözümlenebilmesi adına tasarımcılar ve mimarlar tarafından daha büyük sorumluluklar alınması gereken yeni bir dünya düzeni söz konusudur. İnsan-mekân ilişkisinde bireysel ve toplumsal olarak mekân kullanım sorunlarını çözmeye yönelik bir yapı oluşturulması tasarımcı ve mimarlar için tasarım sürecindeki bir öncelik halini almışır. Daha sürdürülebilir, yaşanabilir, bireyin konfor ve intiyaçlarını gözeten, herkes için tasarıma odaklanmış mekân arayışlarında bütün bu yaklaşımları göz önünde bulundurarak ideal tasarımı gerçekleştirmek hedef olmalıdır. İç mimari ve kullanııılar arasındaki birincil iletişim bugün bireysel çalışma ve yaşam alanlarından toplumsal sosyalleșme ve etkilessim alanlarına kadar tüm mecralarda gözlenmekte ve nesnelerin diziliminden mekânın oluşumuna kadar tüm mimarinin tamamen kullanıcı tarafından koordine edildiği görülmektedir. Bu nedenden ötürü ki, tüm tasarım yaklaşımları doğrultusunda ve diğer tasarım disiplinleri ile ilişkisinde kullanıcı merkezli çalışmaların bütünü iç mekânla ilişkili ve bu ilişkinin temeli de kullanıcı deneyimi tasarımına dayanmaktadır. Mekânda kullanıcı deneyimini ölçümlemeye dair var olan verilerin kullanılmasının yanı sıra yeni teknikler geliştirmek, ar-ge ve uygulama kapsamında sürece dahil etmek tasarımın gerekliliği olarak ortaya çıkmaktadır. Bu araştırma bağlamında hem yeni yetişen tasarımc ve mimarların öğrenme sürecinde hem de sektördeki kıdemlilerin proje uygulama sürecinde iyi bir tasarım adına kullanıı merkezli tasarım ve kullanıcı deneyimi faktörlerini gözetilebilecekleri vurgulanmaktadır. Sadece toplumsal gruplar oluşturarak değil kullanılacak olan mekânın hedef kitlesi üzerinden ya da bireyin ihtiyaçlarına göre kişiselleştirilebilecek tasarımlarla yeni çözümlere odaklanılabilir. Tasarımda modüler olmak, hedef kitle analizi, doğru kullanııı senaryoları oluşturmak gibi birçok yöntem kullanılabileceği gibi kişiselleştirilebilir tasarım mekanizmaları kurgulamak ile de aranan ideal sonuçlar elde edilebilir. Tüm bu değerler kapsamında temel amaç değişen insan ve yaşam faktöründe, kullanıcı merkezli tasarım yaklaşımı üzerinden kullanıcı deneyimi tasarımının iç mekân tasarımına nitelik katacak bir süreç olarak ele alınmasıdır. Kullanıcı-mekân ilişkisinde etkileşim ve deneyimin tasarlanacak yapının başlangıç süreci olarak değerlendirmek talep edilen ideal tasarıma ulaşabilmeyi sağlayabilir. 


\section{Kaynakça}

Acırlı, Z. ve Kandemir, Ö. (2020). IDA-International Design Art and Journal. Tasarım Kavramında Değişen İnsan Faktörü ve Değişen Kapsayıcı Tasarım Yaklaşımları, 2(2)

Chammas, A., Quaresma, M., \&Mont'Alvão, C. (2015). A Closer Look on the User Centred Design. Procedia Manufacturing, 3, 5397-5404.

Dervişoğlu, E. (2008). Beden Mekân Illişkisi: Bedenin Mekânla Kavrayış Üzerinden Değerlendirilmesi. İstanbul Teknik Üniversitesi.

Erap, B. N., Yurttaş, M. K. ve Kariptaş, F. S. (202I). “ Posthuman Space, User Experience in Anthropocene Age”, LivenARCH-VII : OTHER ARCHITECT/URE(S) Congress, 28-30 October, 202I, Trabzon

Hilmioğlu, S. (20I7). Çok Aile Konut Tasarımına Yönelik Bir Evrensel Tasarım Modeli. İstanbul Teknik Üniversitesi.

ISO 924I-2IO (2019) ISO 924I-2 I0. Ergonomics Of Human-System Interaction Part 210: Human-Centred Design For Interactive Systems. www.iso.org, 2019.

Lefebvre, H. (199I). Production of the Space. Basil Blackwell.

Norman, D. (2016). The Design of Everyday Things. In The Design of Everyday

Things . Basic Books. s. 243

Pallasmaa, Y. (2005). The Eyes of the Skin. John Wiley \& SonsLtd, s.4 I

Schulz, N. C. (197I). Existence, Space and Architecture. Studio Vista.

\section{Internet Kaynakları}

Url-I:http://www.mimarlikdergisi.com/index.

cfm?sayfa $=$ mimarlik\&DergiSayi $=36 \mid$ \&ReclD $=2062$ (Son erişim tarihi $:||$ |.03.202 I)

Url-2: https://archello.com/project/oodi-helsinki-central-library\#story-3 (Son erişim tarihi: |2.02.202I)

Url-3: http://ala.fi/work/helsinki-central-library/ (Son erişim tarihi : 08.03.202I)

Url-4:https://www.arkitera.com/proje/oodi-helsinki-merkez-kutuphanesi/ (Son erişim tarihi : 05.12.202I)

Url-5:https://www.avontuura.com/forum-groningen-by-nl-architects/( Erişim tarihi: 22.02.202I)

\section{Görsel Kaynaklar}

Şekil I - İnsan Merkezli Tasarım ve Tasarım Yaklaşımları, ilk yazar tarafından çizilmiştir, 2021, İstanbul

Şekil 2 - Mekâna Bağlı Kullanıcı Deneyimi Tasarımı (UXD), ilk yazar tarafından çizilmiştir, 202।, İstanbul

Şekil 3 - Kullanııı Deneyimi Tasarımı Süreci (UXD), ilk yazar tarafından çizilmiştir, 2021, İstanbul 